\title{
Covidom, a Telesurveillance Solution for Home Monitoring Patients With COVID-19
}

Youri Yordanov $^{1}$, MD, PhD; Agnes Dechartres ${ }^{2}, \mathrm{MD}, \mathrm{PhD}$; Xavier Lescure ${ }^{3}, \mathrm{MD}, \mathrm{PhD}$; Caroline Apra ${ }^{4}$, MD; Pascaline Villie $^{5}$, MS; Jerome Marchand-Arvier ${ }^{5}$, MS; Erwan Debuc ${ }^{6}$, MD; Aurélien Dinh ${ }^{7}$, MD; Patrick Jourdain ${ }^{8}$, MD, PhD; On Behalf Of The AP-HP / Universities / Inserm COVID-19 Research Collaboration ${ }^{9}$

\footnotetext{
${ }^{1}$ Sorbonne Université, AP-HP, Hôpital Saint Antoine, Service d'Accueil des Urgences, INSERM, Institut Pierre Louis d'Epidémiologie et de Santé Publique, UMR-S 1136, Paris, France

${ }^{2}$ Sorbonne Université, INSERM, Institut Pierre Louis d'Epidémiologie et de Santé Publique, UMR-S 1136, AP-HP, Hôpital Pitié Salpêtrière, Département de Santé Publique, Centre de Pharmacoépidémiologie de l'AP-HP (Cephepi), Paris, France

${ }^{3}$ Department of Infectious and Tropical Diseases, Bichat-Claude Bernard University Hospital, Assistance Publique-Hôpitaux de Paris, Paris, France

${ }^{4}$ Service de Neurochirurgie, Hôpital Pitié Salpêtrière, Assistance Publique-Hôpitaux de Paris - Sorbonne Université, Paris, France

${ }^{5}$ Assistance Publique-Hôpitaux de Paris, Paris, France

${ }^{6}$ Service d'Accueil des Urgences, Hôpital Saint Antoine, Assistance Publique-Hôpitaux de Paris - Sorbonne Université, Paris, France

${ }^{7}$ Infectious Disease Department, R Poincaré University Hospital, Garches, Assistance Publique-Hôpitaux de Paris - Paris Saclay University, Paris, France

${ }^{8}$ Université Paris Saclay, AP-HP, Hopital du Kremlin Bicêtre, Service de Cardiologie, Département médico-universitaire Coeur Vaisseaux Reins, Kremlin Bicêtre, France, Kremlin-Bicetre, France

${ }^{9}$ AP-HP / Universities / Inserm COVID-19 Research Collaboration, Paris, France
}

\section{Corresponding Author:}

Youri Yordanov, MD, PhD

Sorbonne Université, AP-HP, Hôpital Saint Antoine, Service d'Accueil des Urgences, INSERM, Institut Pierre Louis d'Epidémiologie et de Santé Publique, UMR-S 1136

34 rue Crozatier

Paris

France

Phone: 33171970869

Email: youri.yordanov@aphp.fr

\begin{abstract}
In a matter of months, COVID-19 has escalated from a cluster of cases in Wuhan, China, to a global pandemic. As the number of patients with COVID-19 grew, solutions for the home monitoring of infected patients became critical. This viewpoint presents a telesurveillance solution-Covidom-deployed in the greater Paris area to monitor patients with COVID-19 in their homes. The system was rapidly developed and is being used on a large scale with more than 65,000 registered patients to date. The Covidom solution combines an easy-to-use and free web application for patients (through which patients fill out short questionnaires on their health status) with a regional control center that monitors and manages alerts (triggered by questionnaire responses) from patients whose health may be deteriorating. This innovative solution could alleviate the burden of health care professionals and systems while allowing for rapid response when patients trigger an alert.
\end{abstract}

(J Med Internet Res 2020;22(10):e20748) doi: 10.2196/20748

\section{KEYWORDS}

COVID-19; coronavirus disease; home monitoring; telesurveillance; monitoring; patient; infectious disease; app

\section{Introduction}

In less than 7 months, COVID-19 escalated from a cluster of cases in Wuhan, China, to a global pandemic with more than 15 million infected people and 630,000 deaths in over 200 countries [1,2]. The clinical characteristics of patients with
COVID-19 are well described, with most presenting mild symptoms and fatalities occurring mainly in chronically ill and older patients [3-7]. In addition to being a therapeutic challenge for physicians and health care workers, the exponential increase in patients with COVID-19, and their considerable length of stay in a hospital, could exceed health care systems' capacities 
[8-12]. To allow hospitals to focus on vulnerable and the most severely ill patients, those with COVID-19 but presenting no serious symptoms are being sent home [13]. However, for $10 \%$ to $15 \%$ of these patients, the disease will become severe, which requires surveillance $[13,14]$. Various systems have been set up to carry out this surveillance, often involving general practitioners (GPs) and telephone-based and/or home visits, or the use of telehealth technologies for virtual consultations $[15,16]$. However, all these systems rely on the individual management of every patient by a single doctor (GP, infectious disease specialist, or any other specialist involved in COVID-19 management). In a pandemic situation, GPs and infectious disease specialists are scarce resources and should be mobilized wisely $[15,17,18]$.

To offer alternatives to patients while reserving medical resources for the situations that require it, the Greater Paris University Hospitals (Assistance Publique-Hôpitaux de Paris, [APHP]), in collaboration with regional GP organizations and a software company specializing in patient digital pathways, quickly developed a remote telesurveillance solution named Covidom for the home monitoring of patients with COVID-19.

\section{The Covidom Solution}

Covidom combines an easy-to-use and free web application for patients with a regional control center to manage alerts (Figure
1). Patients with a suspected or confirmed case of COVID-19, according to the French public health authorities' definition of COVID-19 infection [19], are registered by a physician after receiving a brief description of the Covidom solution and providing oral consent to participate. Registration can be performed either as part of outpatient management after diagnosis (ie, after a visit to an emergency department or consultation with a GP or another specialist) or at the time of discharge after COVID-19-related hospitalization. Registration is a simple procedure where patients provide simple baseline characteristics, including age, gender, phone number or email address, date of first symptoms, and risk profile. A high-risk profile includes the presence of cardiovascular disease, diabetes, chronic lung disease, immunodeficiency (transplant, active cancer treatment, uncontrolled HIV infection, etc), third trimester of pregnancy, or age $>65$ years [19].

Patients then receive a registration link via a short mobile message or email, through which they complete registration and provide electronic consent for the Covidom telesurveillance program. They are informed of the potential use of their anonymized data for research purposes. This use was approved by the scientific and ethical committee of APHP (IRB00011591).

The data is available upon request for academic researchers.

Figure 1. The Covidom solution: patient pathway and regional control center organization. GP: general practitioner, SAMU: Service d'Aide Médicale Urgente.

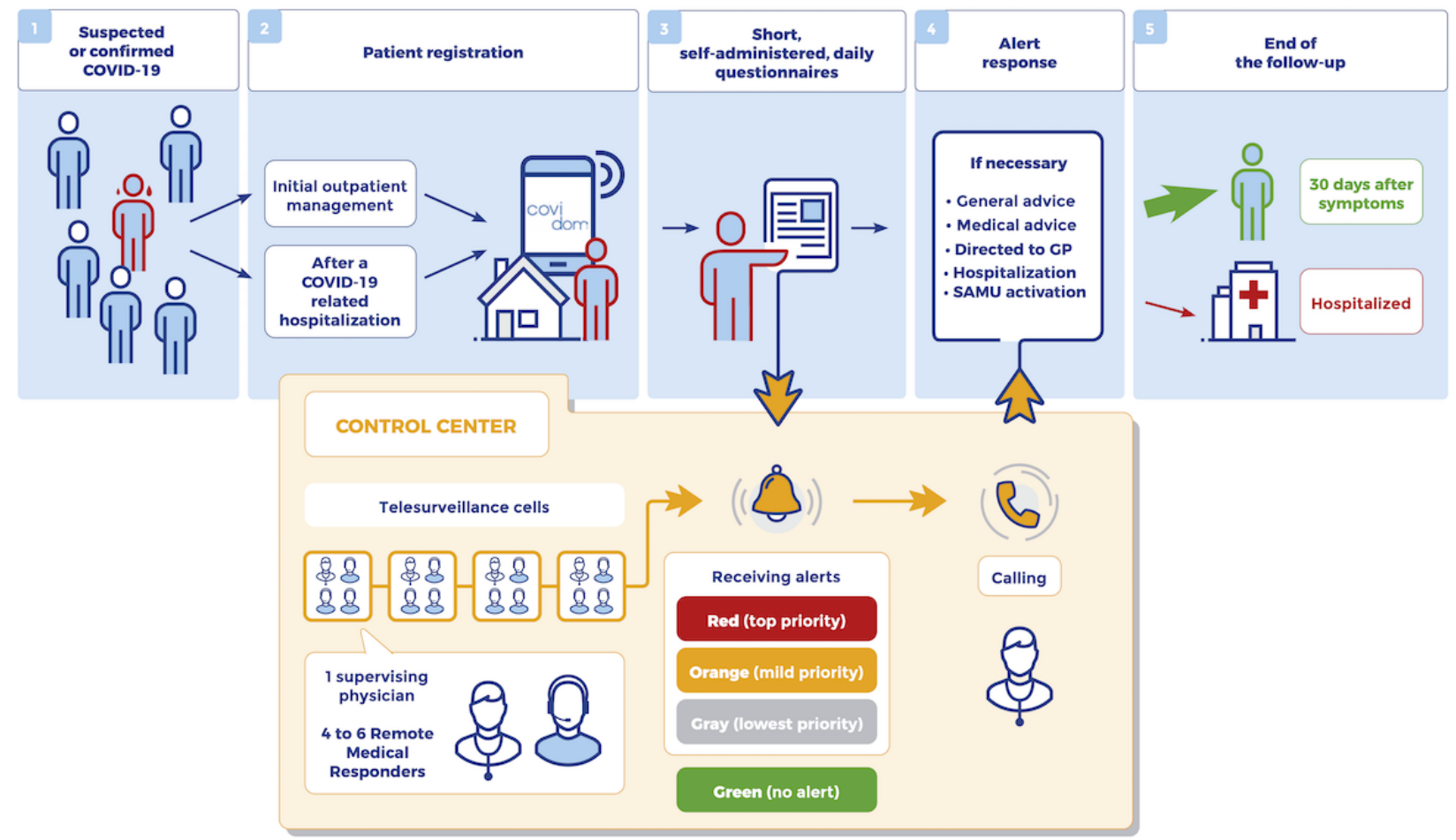

\section{The Covidom Web Application}

The web application was designed to be straightforward and intuitive to use for patients. The interface of the application can be seen in Figure 2. Patients complete one or two self-administered daily monitoring questionnaires for a duration of 30 days after symptom onset. These questionnaires involve fewer than 10 short and standardized questions. The questionnaires can be accessed via computer or smartphone, and patients are informed by mobile message or email to complete them with a reminder in case of no response. The questions ask patients to self-report their respiratory rate, heart rate, temperature, respiratory uneasiness (adapted from the modified Borg dyspnea scale [20]), nausea, malaise, as well as 
psychological discomfort and difficulties dealing with lockdown measures. Patients assessed as high risk by the physician who performed their initial evaluation need to complete the questionnaires twice a day, while low-risk patients respond only once a day. The answers to these monitoring questionnaires can trigger different types of alerts at the regional control center. These questionnaires were elaborated and tested by a panel of multidisciplinary health care professionals (infectious diseases, emergency physicians, GPs, and telesurveillance specialists).
In the web application, patients can also find information on the virus and how to mitigate transmission risk (ie, French health ministry documents); how to measure one's own temperature, heart rate, and respiratory rate; and how to seek psychological support if needed. In case of an emergency, patients are advised to directly contact the national emergency number by dialing 15 (Service d'Aide Médicale Urgente [SAMU]).

Figure 2. Covidom web application screenshots.

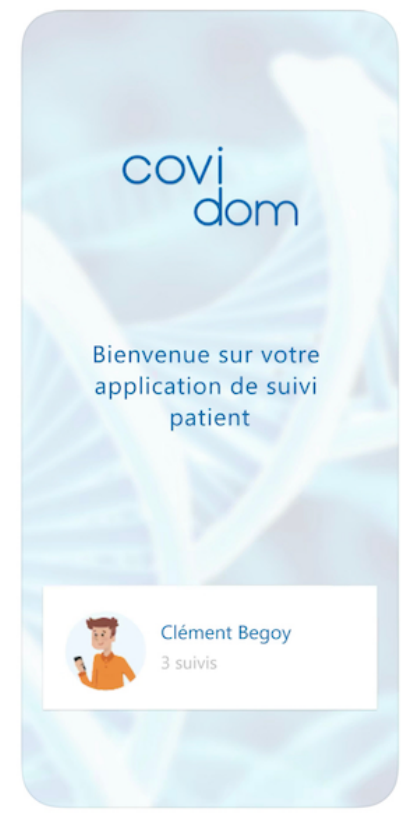

\section{The Covidom Regional Control Center}

The Covidom regional control center is open from 8 AM to 8 PM, 7 days a week, and covers all patients using the Covidom system in the greater Paris area (12 million inhabitants). It is built on the concept of autonomous remote monitoring cells. Each cell is made up of 4 to 6 trained remote monitoring responders (RMRs) and a supervising physician, all physically colocated at the Covidom regional control center, equipped with face masks and adhering to physical distancing measures. The mission of the cells is to handle the alerts generated by patient answers to the daily or twice-daily questionnaires. Patient answers are classified into 4 categories by an automated algorithm:

- No alert: everything is considered normal, no need for further action;

- Orange alert: some of the answers are above a certain threshold. These alerts need a response from the regional control center;

- Red alert: some of the answers suggest that the patient's condition may be deteriorating. These alerts need a response from the control center, with the highest level of priority;

- Gray alert: the patients did not answer the questionnaire. These alerts need a response from the control center and patients need to be called, but the level of priority is low.

To handle the alerts, RMRs access the patient record and contact patients by phone to identify the cause of the alert. If needed, the supervising physician of the cell can intervene and assess the patient over the phone. An alert is considered handled once the RMR or the physician offers a solution to the patient: general advice, medical advice, directed to their GP, hospitalization, or contact with the SAMU. Infectious disease wards, emergency departments, or the SAMU can be contacted directly by the control center using dedicated phone numbers. If necessary, these contacts could result in a mobile intensive care unit staffed with emergency physicians sent to the patient's home or a regular ambulance with a paramedic sent to assess the patient and transport them to a hospital. Of note, in the case of remote medical assessment, Covidom personnel does not charge a fee.

The control center cell physicians and RMRs are volunteers from different backgrounds (Multimedia Appendix 1). Physicians are rarely infectious disease specialists, GPs, or emergency physicians since those individuals are on the frontline caring for patients in need of acute care. Covidom personnel are mostly other specialists with decreased activity because of the lockdown who wanted to contribute to crisis management. All physicians and RMRs receive theoretical and practical training, the intensity of which depends on the person's profile. They do not receive any financial incentives, but nonfinancial incentives are offered, such as meals or transportation solutions if public transport is not available. All volunteers have to sign an individual contract with the APHP for medical confidentiality, insurance, and liability reasons. On-site psychological support is available if needed. 
Overview of Covidom as of May 19, 2020

In the period between March 9 to May 19, 2020, 57,182 patients were registered in Covidom with a suspected or confirmed case of COVID-19. These patients were referred by 1709 physicians working in 30 public and 70 private hospitals and by 2131 GPs (in private or public medical practices). Most patients were referred as part of their initial outpatient care $(50,020 / 57,182$, $87.5 \%$ ) while 7162 were included at hospitalization discharge. Out of these patients, $84.5 \%(48,290 / 57,182)$ confirmed their registration, $8.4 \%(4057 / 48,290)$ never answered a surveillance questionnaire, and $70.6 \%(34,104 / 48,290)$ answered questionnaires for more than 7 days. A total of 104 patients were offered alternatives, by contacting patients' GPs to organize a follow-up, as they had trouble using the system (eg, uncomfortable using the required technologies or language issues). Patients' mean age was 43.7 years (SD 15.8) and a majority were female $(33,542 / 48,290,58.7 \%)$ (Table 1$)$. The patients' risk profile was recorded as high in 60.3\% (3315/5493) of cases included at hospital discharge and in $39.9 \%$ $(17,082 / 42,797)$ of cases included as part of their initial outpatient care.

During follow-up (phases 3 and 4 of the patient's pathway in Figure 1), patients triggered 21,873 red alerts and 211,160 orange alerts. Red alerts were handled in a median time of 2 min and $20 \mathrm{~s}$ (IQR $46 \mathrm{~s}$ to 6 min and $54 \mathrm{~s}$ ) and orange alerts were handled in $10 \mathrm{~min}$ and $34 \mathrm{~s}$ (IQR $1 \mathrm{~min}$ and $28 \mathrm{~s}$ to $93 \mathrm{~min}$ and $51 \mathrm{~s}$ ). We present in Figure 3 the weekly averaged counts of patients managed using Covidom and the alerts generated. From March 30, 368 alerts resulted in contact with SAMU (via the national emergency number) through the regional control center (over 215,056 alerts by 41,758 patients). As of May 19, $72.0 \%(34,767 / 48,290)$ of patients had their follow-up terminated, $1.1 \%(544 / 48,290)$ had been hospitalized or rehospitalized, and $0.1 \%$ had died $(39 / 48,290)$.

Table 1. General characteristics of and reasons for end of follow-up among patients using Covidom, as of May 19, 2020.

\begin{tabular}{|c|c|c|c|}
\hline Characteristic & $\begin{array}{l}\text { Posthospital discharge manage- } \\
\text { ment }(\mathrm{n}=5493)\end{array}$ & $\begin{array}{l}\text { Initial outpatient management } \\
(\mathrm{n}=42,797)\end{array}$ & Total $(\mathrm{N}=48,290)$ \\
\hline \multicolumn{4}{|l|}{ General characteristics } \\
\hline Age (years), mean (SD) & $48.5(17.2)$ & $42.3(14.9)$ & $43.7(15.8)$ \\
\hline \multicolumn{4}{|l|}{ Gender, n (\%) } \\
\hline Male & 2669 (48.6) & $16,260(38.0)$ & $23,564(41.2)$ \\
\hline Female & $2818(51.3)$ & $26,488(61.9)$ & $33,542(58.7)$ \\
\hline \multicolumn{4}{|l|}{ Risk profile, n (\%) } \\
\hline High-risk profile & $3315(60.3)$ & $17,082(39.9)$ & $24,756(43.3)$ \\
\hline \multicolumn{4}{|l|}{ Reason for end of follow-up, n (\%) } \\
\hline Automatic termination of follow-up after 30 days & $3957(72.0)$ & $30,810(72.0)$ & $34,767(72.0)$ \\
\hline Follow-up ended early at patient's request ${ }^{\mathrm{a}}$ & $831(15.1)$ & $7473(17.5)$ & $8304(17.2)$ \\
\hline Ongoing follow-up & $590(10.74)$ & $4046(9.45)$ & $4636(9.60)$ \\
\hline Hospital admission & $111(2.0)$ & $433(1.0)$ & $544(1.1)$ \\
\hline Death & $4(0.1)$ & $35(0.1)$ & $39(0.1)$ \\
\hline
\end{tabular}

${ }^{a}$ Follow-up ended early at patient's request: no more symptoms, no longer felt like answering questionnaires, or any other reason left at the patient's discretion. 
Figure 3. Number of patients and alerts over time.

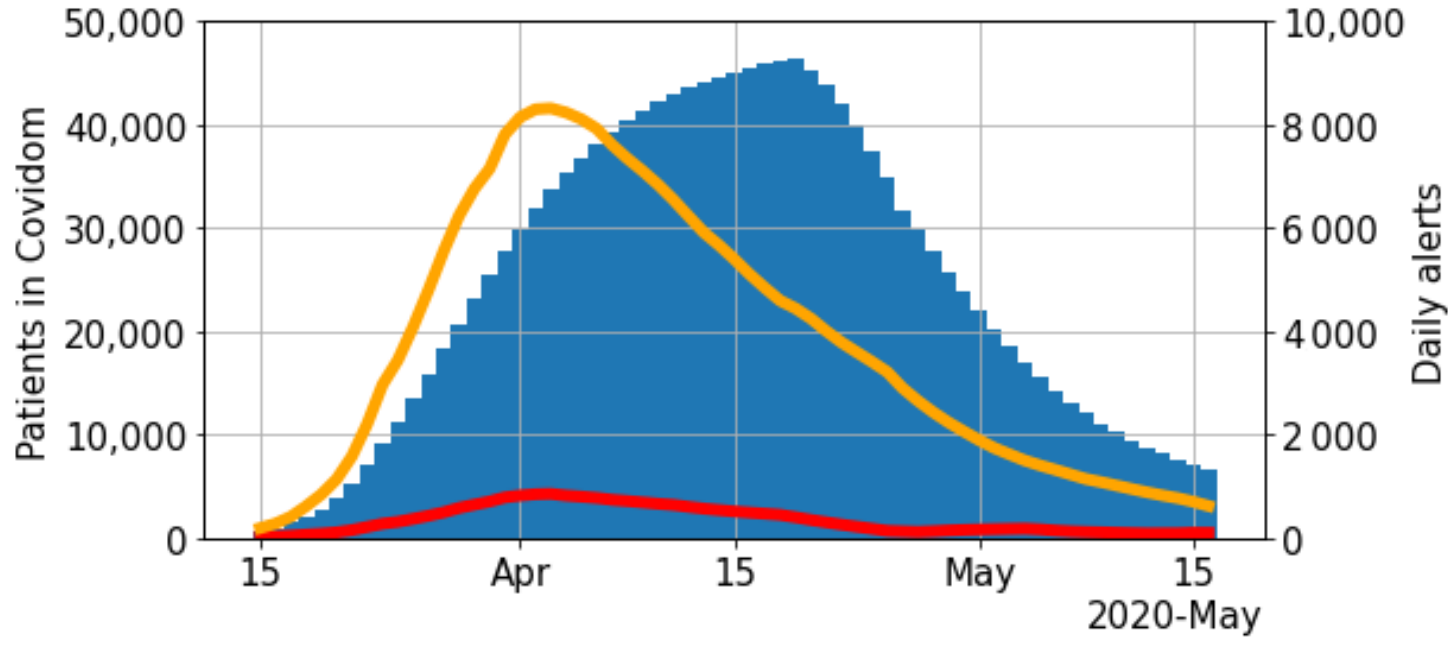

\section{Implications, Future Works, and Limitations}

To our knowledge, Covidom is the first and largest telesurveillance solution $(65,202$ patients as of July 24) described for the home monitoring of COVID-19 cases with the aim to alleviate the burden of health care professionals and systems. Telesurveillance has never been used in acute infectious diseases at this scale until now [21]; previously, it had been mostly used in chronic diseases [22,23]. Most health care systems are based on in-person interactions between patients and their clinicians, but in a pandemic context, this situation is highly challenged, and health digital solutions are of interest both to patients and to the health care system [15-17]. From patients' perspective, this system can provide reassurance by daily monitoring their condition with a procedure in place in case of worsening symptoms. Patients often worry about the potential and sudden worsening of symptoms during a lockdown, due to limited social contact [24,25]. This telesurveillance system allows for close but minimally invasive surveillance using daily short questionnaires with fewer than 10 questions, which is easily accepted by patients [26]. From the public health perspective, this system may offer a partial virtual safety net to rapidly detect any signs of deterioration in patients with COVID-19, while making proper use of scarce resources via a 2-step process where automated alert algorithms can trigger a medical response when needed. Automatic algorithms and health care professionals based in a regional control center could help reserve health care workers and hospital beds for the patients who need them most and alleviate pressure on the health care system.

Such tools also have the major advantage of ensuring close surveillance while avoiding physical contact, which can help limit the spread of the virus and possible health care worker contamination. Providing appropriate care while preserving one's own health is a strong motivation for health care workers to rapidly develop and widely use virtual health care solutions [27].

Finally, Covidom represents an important source of epidemiologic data, providing an opportunity to increase our knowledge of the disease, in particular of its common but least studied mild form. Covidom was initially deployed in the greater Paris area but is being extended to other French regions using the same principles: use of a web application with a dedicated regional control center whose functioning may depend on the region. Because of its simplicity and quick response, this solution could be easily adapted in other countries.

Of course, the Covidom solution needs to be thoroughly evaluated; in particular, the efficiency and ability of the alerts to detect patients at high risk of deterioration and the medico-economic impact of such a solution need evaluation. To do this, we will link the Covidom database with hospitals and national social security databases to identify patients who directly contacted them or were self-referred to an emergency department.

The Covidom system was sustainable during the lockdown due to the personnel availability that resulted from nonurgent elective procedures or appointments being rescheduled; most of the workforce comprised salaried employees (as opposed to a pay-per-service system). We observed significant fluctuations in the availability of human resources. At first, and due to the lockdown, many volunteers offered their help. Since lockdown measures were lifted (May 11, 2020) and as control center cell physicians and RMRs progressively resumed their usual activities, finding enough personnel has become more of a challenge. Adapting the Covidom solution and offering alternatives to patients who had difficulty with the system (unfamiliar with these technologies or language issues) was done by connecting these patients to their GPs. However, additional options could have included translated versions of the questionnaires and the other available documents to help patients with language issues. Surveillance could also have been more flexible as it was found to be short for some patients with recurrent or persistent symptoms, while others would have preferred to stop the follow-up as soon as the symptoms disappeared. Finally, sharing the patients' Covidom file, or a summary of it, with patients' GPs was not done. 


\section{Conclusion}

Covidom is an innovative solution for the home monitoring of patients with COVID-19. The model could be easily transposed to other countries or contexts. Most patients have been included as part of their initial outpatient management, making Covidom the largest cohort to date of patients with a mild case of COVID-19, which is the form that occurs in a majority of patients but is least studied. Using telesurveillance solutions like Covidom could augment health care systems' abilities by allowing them to monitor patients and promptly identify worsening symptoms, while limiting the need to travel and the risk of contamination.

\section{Acknowledgments}

We thank Falzon Alexandre, Fayolle Guillaume, Laporte Fanny, Amélie Tortel, and the Nouveal-e Santé team for their help with the web application and regional center surveillance interface development. We also thank Debastard Laurent, Grenier Alexandre, Hody Julien, Penn Thomas, and the Paris region URPS (Union régionale des professionnels de santé) for their help in the development and dissemination of the Covidom solution.

This study received funding from the Programme Hospitalier de Recherche Clinique 2020 of the French Ministry of Health and a research grant from the APHP-Fondation de France. The Covidom platform received funding from the EIT Health for COVID-19 research.

Members of the AP-HP / Universities / Inserm COVID-19 research collaboration are as follows: the Writing Committee (Youri Yordanov, Agnes Dechartres, François-Xavier Lescure, Caroline Apra, Pascaline Villie, Jerôme Marchand-Arvier, Erwan Debuc, Aurélien Dinh, and Patrick Jourdain); the Data-Sciences Committee (Caroline Apra, Charlotte Caucheteux, Luc Jaulmes, Alexandre Gramfort, Jenny Mansour, and Arthur Mensch); the Scientific Committee (Amélie Aime-Eusebi, Caroline Apra, Alexandre Bleibtreu, Erwan Debuc, Agnes Dechartres, Laurène Deconinck, Aurélien Dinh, Patrick Jourdain, Christine Katlama, Josselin Lebel, François-Xavier Lescure, and Youri Yordanov); the Covidom Regional Center Steering Commitee (Yves Artigou, Amélie Banzet, Elodie Boucheron, Christiane Boudier, Edouard Buzenac, Marie-Claire Chapron, Dalhia Chekaoui, Laurent De Bastard, Erwan Debuc, Aurélien Dinh, Alexandre Grenier, Pierre-Etienne Haas, Julien Hody, Michèle Jarraya, Patrick Jourdain, Louis Lacaille, Aurélie Le Guern, Jeremy Leclert, Fanny Male, Jerôme Marchand-Arvier, Emmanuel Martin-Blondet, Apolinne Nassour, Oussama Ourahou, Thomas Penn, Ambre Ribardiere, Nicolas Robin, Camille Rouge, Nicolas Schmidt, and Pascaline Villie); and the Centre de Pharmaco-Epidémiologie de l'AP-HP (Sofia Zemouri).

\section{Authors' Contributions}

YY and AD were involved in the study conception, data extraction, data analysis, interpretation of results, and drafting of the manuscript. XL was involved in the Covidom solution development, interpretation of results, and critical revision of the manuscript. CA was involved in the data extraction, data analysis, interpretation of results, and critical revision of the manuscript. PV, JM-A, $\mathrm{ED}, \mathrm{ADi}$, and PJ were involved in the Covidom solution development, study conception, interpretation of results, and critical revision of the manuscript.

YY (the manuscript's guarantor) affirms that the manuscript is an honest, accurate, and transparent account of the study being reported; that no important aspects of the study have been omitted; and that any discrepancies from the study have been explained.

\section{Conflicts of Interest}

None declared.

\section{Multimedia Appendix 1}

List of physicians, supervising physicians, and remote monitoring responders part of the Covidom system. [DOC File, 172 KB-Multimedia Appendix 1]

\section{References}

1. Lu H, Stratton CW, Tang Y. Outbreak of pneumonia of unknown etiology in Wuhan, China: The mystery and the miracle. J Med Virol 2020 Apr;92(4):401-402 [FREE Full text] [doi: 10.1002/jmv.25678] [Medline: $\underline{31950516}$ ]

2. Coronavirus Update (Live), 433,760 Cases and 631,402 Deaths from COVID-19 Virus Pandemic. Worldometer. 2020. URL: https://www.worldometers.info/coronavirus/ [accessed 2020-07-23]

3. Wang X, Fang J, Zhu Y, Chen L, Ding F, Zhou R, et al. Clinical characteristics of non-critically ill patients with novel coronavirus infection (COVID-19) in a Fangcang Hospital. Clin Microbiol Infect 2020 Aug;26(8):1063-1068 [FREE Full text] [doi: 10.1016/j.cmi.2020.03.032] [Medline: 32251842]

4. Zhou F, Yu T, Du R, Fan G, Liu Y, Liu Z, et al. Clinical course and risk factors for mortality of adult inpatients with COVID-19 in Wuhan, China: a retrospective cohort study. The Lancet 2020 Mar 28;395(10229):1054-1062. [doi: 10.1016/S0140-6736(20)30566-3] [Medline: $\underline{\text { 32171076] }}$ 
5. Huang C, Wang Y, Li X, Ren L, Zhao J, Hu Y, et al. Clinical features of patients infected with 2019 novel coronavirus in Wuhan, China. Lancet 2020 Feb 15;395(10223):497-506 [FREE Full text] [doi: 10.1016/S0140-6736(20)30183-5] [Medline: 31986264]

6. Wu C, Chen X, Cai Y, Xia J, Zhou X, Xu S, et al. Risk Factors Associated With Acute Respiratory Distress Syndrome and Death in Patients With Coronavirus Disease 2019 Pneumonia in Wuhan, China. JAMA Intern Med 2020 Jul 01;180(7):934-943 [FREE Full text] [doi: 10.1001/jamainternmed.2020.0994] [Medline: $\underline{32167524]}$

7. Richardson S, Hirsch JS, Narasimhan M, Crawford JM, McGinn T, Davidson KW, the Northwell COVID-19 Research Consortium, et al. Presenting Characteristics, Comorbidities, and Outcomes Among 5700 Patients Hospitalized With COVID-19 in the New York City Area. JAMA 2020 May 26;323(20):2052-2059 [FREE Full text] [doi: 10.1001/jama.2020.6775] [Medline: 32320003]

8. Legido-Quigley H, Mateos-García JT, Campos VR, Gea-Sánchez M, Muntaner C, McKee M. The resilience of the Spanish health system against the COVID-19 pandemic. Lancet Public Health 2020 May;5(5):e251-e252 [FREE Full text] [doi: 10.1016/S2468-2667(20)30060-8] [Medline: 32199083]

9. Watkins J. Preventing a covid-19 pandemic. BMJ 2020 Feb 28;368:m810. [doi: 10.1136/bmj.m810] [Medline: $\underline{32111649]}$

10. Armocida B, Formenti B, Ussai S, Palestra F, Missoni E. The Italian health system and the COVID-19 challenge. Lancet Public Health 2020 May;5(5):e253 [FREE Full text] [doi: 10.1016/S2468-2667(20)30074-8] [Medline: 32220653]

11. Lewnard J, Liu V, Jackson M, Schmidt M, Jewell B, Flores J, et al. Incidence, clinical outcomes, and transmission dynamics of severe coronavirus disease 2019 in California and Washington: prospective cohort study. BMJ 2020 May 22;369:m1923. [doi: 10.1136/bmj.m1923] [Medline: 32444358]

12. Remuzzi A, Remuzzi G. COVID-19 and Italy: what next? Lancet 2020 Apr 11;395(10231):1225-1228 [FREE Full text] [doi: 10.1016/S0140-6736(20)30627-9] [Medline: $\underline{\text { 32178769] }}$

13. Gandhi RT, Lynch JB, Del Rio C. Mild or Moderate Covid-19. N Engl J Med 2020 Apr 24:e. [doi: 10.1056/NEJMcp2009249] [Medline: 32329974]

14. Report of the WHO-China Joint Mission on Coronavirus Disease 2019 (COVID-19). World Health Organization. 2020 Feb 28. URL: https://www.who.int/publications-detail/ report-of-the-who-china-joint-mission-on-coronavirus-disease-2019-(covid-19) [accessed 2020-06-01]

15. Hollander JE, Carr BG. Virtually Perfect? Telemedicine for Covid-19. N Engl J Med 2020 Apr 30;382(18):1679-1681. [doi: 10.1056/NEJMp2003539] [Medline: 32160451]

16. Mahase E. Covid-19: out-of-hours providers are drafted in to manage non-urgent patients in community. BMJ $2020 \mathrm{Mar}$ 09;368:m959. [doi: 10.1136/bmj.m959] [Medline: $\underline{\text { 32152010] }}$

17. Lurie N, Carr BG. The Role of Telehealth in the Medical Response to Disasters. JAMA Intern Med 2018 Jun 01;178(6):745-746. [doi: 10.1001/jamainternmed.2018.1314] [Medline: 29710200]

18. Keesara S, Jonas A, Schulman K. Covid-19 and Health Care's Digital Revolution. N Engl J Med 2020 Jun 04;382(23):e82 [FREE Full text] [doi: 10.1056/nejmp2005835]

19. Infection au nouveau Coronavirus (SARS-CoV-2), COVID-19, France et Monde. Sante Publique France. URL: https:/ /www.santepubliquefrance.fr/maladies-et-traumatismes/maladies-et-infections-respiratoires/infection-a-coronavirus/articles/ infection-au-nouveau-coronavirus-sars-cov-2-covid-19-france-et-monde [accessed 2020-04-27]

20. Muza SR, Silverman MT, Gilmore GC, Hellerstein HK, Kelsen SG. Comparison of Scales Used to Quantitate the Sense of Effort to Breathe in Patients with Chronic Obstructive Pulmonary Disease. Am Rev Respir Dis 1990

Apr;141(4_pt_1):909-913. [doi: 10.1164/ajrccm/141.4_pt_1.909]

21. Eron L. Telemedicine: the future of outpatient therapy? Clin Infect Dis 2010 Sep 15;51 Suppl 2:S224-S230. [doi: 10.1086/653524] [Medline: 20731581]

22. Chaudhry SI, Mattera JA, Curtis JP, Spertus JA, Herrin J, Lin Z, et al. Telemonitoring in patients with heart failure. N Engl J Med 2010 Dec 9;363(24):2301-2309 [FREE Full text] [doi: 10.1056/NEJMoa1010029] [Medline: 21080835]

23. Pinnock H, Hanley J, McCloughan L, Todd A, Krishan A, Lewis S, et al. Effectiveness of telemonitoring integrated into existing clinical services on hospital admission for exacerbation of chronic obstructive pulmonary disease: researcher blind, multicentre, randomised controlled trial. BMJ 2013 Oct 17;347:f6070. [doi: 10.1136/bmj.f6070] [Medline: 24136634]

24. Horesh D, Brown AD. Traumatic stress in the age of COVID-19: A call to close critical gaps and adapt to new realities. Psychol Trauma 2020 May;12(4):331-335. [doi: 10.1037/tra0000592] [Medline: 32271070]

25. Zhang Y, Ma ZF. Impact of the COVID-19 Pandemic on Mental Health and Quality of Life among Local Residents in Liaoning Province, China: A Cross-Sectional Study. Int J Environ Res Public Health 2020 Mar 31;17(7):e [FREE Full text] [doi: 10.3390/ijerph17072381] [Medline: 32244498]

26. Sahlqvist S, Song Y, Bull F, Adams E, Preston J, Ogilvie D, iConnect consortium. Effect of questionnaire length, personalisation and reminder type on response rate to a complex postal survey: randomised controlled trial. BMC Med Res Methodol 2011 May 06;11(1):62 [FREE Full text] [doi: 10.1186/1471-2288-11-62] [Medline: 21548947]

27. Webster P. Virtual health care in the era of COVID-19. Lancet 2020 Apr 11;395(10231):1180-1181 [FREE Full text] [doi: 10.1016/S0140-6736(20)30818-7] [Medline: 32278374] 


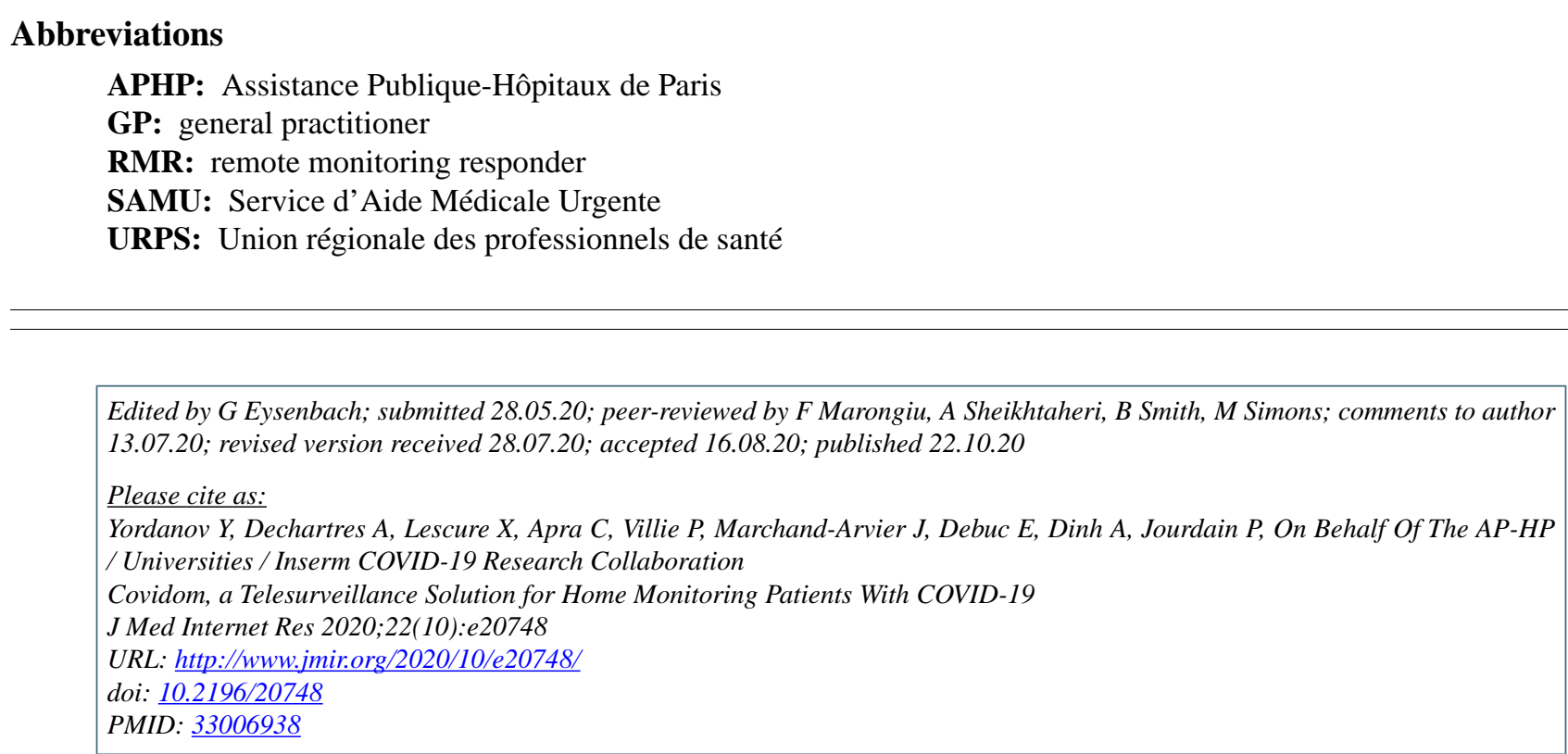

(C)Youri Yordanov, Agnes Dechartres, Xavier Lescure, Caroline Apra, Pascaline Villie, Jerome Marchand-Arvier, Erwan Debuc, Aurélien Dinh, Patrick Jourdain, On Behalf Of The AP-HP / Universities / Inserm COVID-19 Research Collaboration. Originally published in the Journal of Medical Internet Research (http://www.jmir.org), 22.10.2020. This is an open-access article distributed under the terms of the Creative Commons Attribution License (https:/creativecommons.org/licenses/by/4.0/), which permits unrestricted use, distribution, and reproduction in any medium, provided the original work, first published in the Journal of Medical Internet Research, is properly cited. The complete bibliographic information, a link to the original publication on http://www.jmir.org/, as well as this copyright and license information must be included. 